\title{
Scale-dependent location of hydrothermal vents: Stress field models and infrared field observations on the Fossa Cone, Vulcano Island, Italy
}

\author{
A. Schöpa $*$, M. Pantaleo, T.R. Walter
}

Helmholtz Centre Potsdam, GFZ German Research Centre for Geosciences, Telegrafenberg, D-14473 Potsdam, Germany

* Corresponding author at: Now at: University of Bristol, Department of Earth Sciences, Wills Memorial Building, Queens Road, Bristol BS8 1RJ, United Kingdom.

E-mail address: anne.schopa@bristol.ac.uk (A. Schöpa).

Journal of Volcanology and Geothermal Research 203 (2011) 133-145

doi:10.1016/j.jvolgeores.2011.03.008

Keywords:

hydrothermal vents gas monitoring Vulcano Island volcano stress field finite element method infrared

\begin{abstract}
Hydrothermal venting occurs on numerous volcanoes of various age, setting, topographic and structural expression. Vent locations are commonly found not within volcanic craters only, but predominantly at the crater margins and topographic highs. A case example is Vulcano Island, Italy, where the control on such vent locations along crater margins remained poorly understood, however. This paper describes numerical models combined with field observations and infrared imaging to explore the mechanisms that control the ascent paths of fluids in the Fossa cone on Vulcano. Using finite element modelling we calculate the gravitational stress in the volcanic edifice imposed by the topography. Results predict hydrofractures to be arranged in radial patterns at depth and in concentric patterns close to the surface. Furthermore, low compressive stress values are found at the rims of the nested craters. We compare the stress models to fumarole field data: Using a forward looking infrared camera we recorded images of the entire cone. Images were assembled to a mosaic and geocoded, providing the first map of a remotely sensed temperature field in high resolution at La Fossa. The degassing and high temperature anomalies are found to be located mainly at the crests of the craters, predominately in the northern and southern sector of the main crater. Therefore, the stress distribution favours and indeed corresponds to the occurrence of fumaroles at La Fossa. The stress models also yield compression at the bottom of the crater where temperatures are cool. Thus, we consider that the overall distribution of the fumaroles at the Fossa cone is controlled by topography. Additional mechanisms contribute to the exact position of the degassing sites: The influence of the lithological control seems to be strong in the southwestern part of the crater where the fumaroles are located 10-20 m below the inner crater rim in bedded strata. In the northern part of the crater, the exhalation sites can mainly be found at surface fractures and cracks emphasizing the structural control on the location of the fumaroles at this sector of the Fossa cone. Using combined theoretical modelling and field observations, this study helps to shed light into the processes directing fluids in volcanic edifices elsewhere and might contribute to the evaluation of upcoming hazard scenarios.
\end{abstract}

\section{Introduction}

Fumarolic activity, the exhalation of steam and gases at the Earth's surface, is observed at many volcanic centres. The understanding of these is of major importance, as inference about 
geothermal and ore exploitation is based on locations and expressions of fumaroles. The exact position of the degassing sites, however, is poorly understood and may be controlled by several interacting factors.

The most discussed control is tectonic in origin, including volcano- tectonic and regional tectonic structures: Fluids follow the least effort principle thus preferably migrate along faults where the permeability is high. The volcano-tectonic control on the position of fumaroles is obvious at calderas where the exhalation sites are often bound to the ring faults (e. g. Chesner and Rose, 1991). The regional tectonic control is obvious on the Reykjanes Peninsula in Iceland, where the geothermal areas follow the trends of rift related faults (Arnórsson, 1995).

Although most fumarolic sites are thought to be controlled by structures alone, we herein explore also alternative possibilities. One is derived from magma ascent studies that assume a strong influence of the stress field induced by topography. The body load of a volcanic pile might affect paths of hydrofractures filled with gases, waters and magmas. As such hydrofractures form parallel to the maximum compressive principal stress and normal to the minimum compressive principal stress (Anderson, 1951) the stress field imposed by the load of gravity in the volcanic structure might have a strong influence on the location and intensity of upcoming vents. Hydrofractures filled with magma (dikes) and with hydrothermal fluids are thought to follow the same physical principles (Gudmundsson, 2009).

Among the first to study this problem, Fiske and Jackson (1972) suggested that the development of the Hawaiian rift zones is rather influenced by the load of the volcanic edifices than by the regional tectonic fabrics. As they observed that dikes propagate parallel to the long axis of their ridge shaped gelatin models, they inferred that the minimum compressive principal stress is orientated horizontally and perpendicular to the long axis of a volcano. Furthermore, Fiske and Jackson (1972) noticed that further injected dikes follow their predecessor on parallel paths and assume that the orientation of newly developing dikes and rifts will be parallel to topographic contours of the older volcanic piles. McGuire and Pullen (1989) studied the orientation of eruptive fissures at Mt. Etna and proposed that the gravitational stress regime in most parts of the volcanic edifice directs dikes parallel to the headwall of the Valle del Bove. Similar was observed at the Canary Islands (Walter and Schmincke, 2002), at Stromboli (Acocella et al., 2006) and at the Galapagos Islands of Fernandina and Isabela (Chadwick and Dieterich, 1995) where eruptive fissures are circumscribing calderas and/or landslide headwalls.

Taken forward to fumarolic activity at volcanic craters, this may lead us to the testable hypothesis if crater rims are sites of fumarolic activity. According to the results of McGuire and Pullen (1989) it might even be possible to predict the propagation paths of new fissures what would make a large contribution to upcoming hazard scenarios.

A new phase of activity at Vulcano Island, one of the best-known cratered volcanoes displaying fumarolic activity, motivates our closer look at this edifice. Vulcano was also chosen because of the pronounced topography of the edifice of La Fossa with relatively steep slopes and the presence of fumaroles detectable at high spatial resolution by modern temperature cameras. The active Fossa cone, visited by thousands of tourists each year, holds a large hazard potential as its explosive eruptions are accompanied with bomb fallout, pyroclastic surges and phreatic explosions (Revil et al., 2008).

To better understand the paths of ascending fluids at the Fossa cone, we designed numerical models to test the influence of the gravitational load on the stress field within the volcanic pile. For a three-dimensional model, the real topography of Vulcano Island was extracted from a 
digital elevation model. The positions of degassing sites predicted by the numerical models were compared with infrared field observations.

\section{Geological setting}

Vulcano Island is part of the Aeolian Arc, a highly active volcanic region in the Tyrrhenian Sea, southern Italy. Seven main islands, Stromboli, Panarea, Vulcano, Lipari, Salina, Filicudi and Alicudi, and several seamounts belong to the Aeolian archipelago that is located north of Sicily (Fig. 1). Volcanism of the Aeolian Volcanic District started during the Quaternary and is still lasting today.

Vulcano is the southernmost of the Aeolian Islands located in the central sector of the arc parallel to the Tindari-Letojanni escarpment (De Astis et al., 1997). Together with Salina and Lipari, it forms a volcanic ridge striking NW-SE. Whereas Mazzuoli et al. (1995) and Bonaccorso (2002) report regional extension in the central sector of the Aeolian Arc, Argnani et al. (2007) attribute the NW-SE trending faults in this region as part of a transpressive belt.

The island of Vulcano represents the emerged part of a voluminous stratovolcano rising from the abyssal plane of the South Tyrrhenian Sea basin from $1240 \mathrm{~m}$ below sea level to its highest peak Monte Aria $481 \mathrm{~m}$ above sea level (Favalli et al., 2005). After Lipari and Salina, Vulcano is the third largest of the Aeolian Islands with an area of $21 \mathrm{~km}^{2}$ (Favalli et al., 2005). The island was created during the last $120 \mathrm{ka}$ (Santacroce et al., 2003).

In the north of Vulcano Island, the Fossa cone (Fig. 2) sits in the $2.5 \mathrm{~km}$ wide Caldera della Fossa (Favalli et al., 2005). It is a subcircular composite tuff cone (Santacroce et al., 2003) with a basal diameter of about $2 \mathrm{~km}$ and a maximum elevation of $391 \mathrm{~m}$ above sea level. The volcanic centre of La Fossa became active 6 ka ago (Pareschi et al., 1999; Revil et al., 2008) and is still active today as inferred from fumarolic activity.

The stratigraphy of the Fossa cone is subdivided into six eruptive stages, i.e. Punte Nere, Grotta dei Palizzi, Commenda/Caruggi, Forgia Vecchia, Pietre Cotte and Gran Cratere (Fig. 2) (De Astis et al., 2006). Each stage had different vent localities but underwent a comparable eruptive history with pyroclastic surges at the beginning and the effusion of viscous lava flows at the end of each stage (Revil et al., 2008). Eruptive activity of the Fossa cone shifted from NE to SW, which is evidenced by the intersecting crater rims of different ages (Fig. 2) (Blanco-Montenegro et al., 2007).

Nowadays, fumarolic activity with "crises" of high output rates and temperatures of the exhaling gases characterise the Fossa cone. The extensive fumarolic field is composed of numerous sources at the surface like vents, fractures and cracks, and commonly indirectly investigated based on the associated temperature field: high surface temperatures indicate the location of fumaroles and the surface expression of ascending hot fluids (Harris and Maciejewski, 2000; Chiodini et al., 2007; Harris et al., 2009). These temperature fields were measured throughout the Fossa cone using point-wise probing and interpolation (Barde-Cabusson et al., 2009).

Fumaroles on Vulcano are predominately found at the upper slopes of the Gran Cratere crater (Revil et al., 2008). Ventura (1994) mentioned that NE-SW striking fractures determine the location of fumarolic vents on the Fossa cone. However, using infrared sensing, Harris and Maciejewski (2000) could identify the exact sites of degassing, showing an activity change during the years and that the fumarolic field migrated into the inner crater flank. Since the fumarolic activity has intensified since 2004 (Granieri et al., 2006; Aubert et al., 2008), a deeper 
understanding of the location and potential migration paths of the fumaroles is of vital interest. As we show in the following, the gravitational load of the volcanic edifice is responsible for hydrofracture orientation and therefore provides a first order control on ascending fluids in the Fossa cone. Locally, lithology and tectonic features might also affect fluid ascent.

\section{Finite element modelling}

\subsection{Methodology}

A digital elevation model (DEM) from Vulcano Island with a resolution of $5 \mathrm{~m} \times 5 \mathrm{~m}$ served as a base to extract topographic data of the Fossa cone (Baldi et al., 2000). The DEM was loaded as a three- dimensional model in the Structural Mechanics module of the commercial FEM program COMSOL Multiphysics, to examine the orien- tation and magnitude of gravitational stresses in the volcanic edifice.

We defined the load of gravity $\mathrm{F}=$ @gh where $\varrho$ is the density of the material, $\mathrm{g}$ the gravitational acceleration of the Earth and $h$ the height of the topographic feature. No other force acts on the boundaries of the topographic feature in the model. A linear elastic and isotropic body is considered, with elastic properties set to values suitable for extrusive and intrusive rocks; density @ was $2700 \mathrm{~kg} / \mathrm{m}^{3}$, Poisson's ratio $v$ was 0.25 and Young's modulus E was $50 \mathrm{GPa}$ (Bell, 1992).

Boundary conditions were set as follows: The bottom of the model needed to be placed in large but finite depth (cf. Iverson and Reid, 1992) that its influence on the stresses near the surface of the topography is irrelevant. Therefore, the lower boundary was set at a depth ten times the elevation of the topographic feature (maximum elevation is $400 \mathrm{~m}$ ). This value was chosen by testing the effect of the lower boundary on the stresses in the topographic feature.

No vertical displacement was allowed at the lower boundary of the model. Correspondingly, the vertical boundaries were free to move only in vertical direction. Tests showed that these spatial dimensions and settings are sufficient and that the outer limits of the model do not disturb the results. The results presented in this work are based on the assumption that the island of Vulcano was already in equilibrium with the underlying crust when the Fossa cone was emplaced. This assumption rules out a large flexural response. Consequently, the vertical boundaries of the model are constructed at the limits of the topographic features. With the lateral extent of the Fossa cone, the three-dimensional model had the size of $2250 \mathrm{~m} \times 2250 \mathrm{~m} \times(4000 \mathrm{~m}+$ elevation $)$. As shown in Fig. 3, the mesh is finer at the upper part of the model where we analysed the stress field. A convergence test was performed by moving the boundaries and changing the size of the mesh elements, confirming that the chosen type, position and size of the boundaries and the mesh did not affect the numerical solution.

Our model setup was further validated by comparison to published analytical and other numerical solutions (Schöpa, 2010). In general, the results of this work match well with the solutions presented in Savage et al. (1985), in Dieterich (1988) and also in Martel and Muller (2000). Vertical or lateral material heterogeneities were not consid- ered, because we can only speculate about their distribution in the volcanic pile. A description of possible effects of these and other model limitations can be found in the Discussion section.

\subsection{Modelling results}

In the three-dimensional model of the Fossa cone, the orientation of the principal stresses and the magnitudes of the horizontal and vertical 
stresses were investigated. The trajectories of the principal stresses $\sigma_{1}, \sigma_{2}$ and $\sigma_{3}$ provide information about the orientation of hydrofractures because they will form parallel to the most compressive principal stress and normal to the minimum compressive principal stress (Anderson, 1951). The magnitudes of the horizontal and vertical stresses help to infer the directions whereto fluids would ascent and hence to hypothesise about fumarole locations.

Two cross-sections, striking N-S and $\mathrm{W}-\mathrm{E}$, and cutting through the deepest point at the bottom of the recent crater, Gran Cratere, serve as examples to depict the stress distribution at depth (Fig. 2 ). We use the geological convention thus compression is considered to be positive and the maximum compressive principal stress is $\sigma_{1}$.

The $\sigma_{1}$-trajectories are vertical in the far-field and turn parallel to the topography near the slopes (Figs. 4 and 5). Up to about $50 \mathrm{~m}$ beneath the crater floor, the $\sigma_{1}$-trajectories are sub-horizontally pointing towards the crater rim (Figs. $4 \mathrm{a}, 5 \mathrm{a}$ ). These $\sigma_{1}$-trajectories remain sub-horizontally up to approximately $100 \mathrm{~m}$ depth, then rotating perpendicular to the projection plane. In map view (Fig. 6 ), the $\sigma_{1}$-trajectories generally follow the curvature of the crater rims resulting in a concentric pattern of the trajectories. The map view also shows that $\sigma_{1}$ converges towards the highest point in the southeast of the crater rim.

Profiles show that the $\sigma_{3}$-trajectories are foremost oriented horizontal and parallel to the plane of projection (Figs. 4b, 5b). When approaching the flanks of the volcanic edifice, $\sigma_{3}$ is oriented perpendicular to the surface slopes. Near to the crater floor, $\sigma_{3}$ is vertical, similar as near to the topographic crests of the crater rims.

The magnitude of the horizontal and the vertical stress in the profiles reveals that compression is higher at the bottom of the Gran Cratere crater than at the crests (Figs. 7 and 8). At depth, the vertical and the horizontal stresses increase in compression with one exception: Below the crater, the horizontal stress firstly drops in compression before it increases again with growing depth.

Therefore, low horizontal compression occurs at the crests of the craters, mainly in the southwest and northeast of the volcanic edifice (Fig. 6). In an arcuate fashion, these compression areas follow the crater rims of Punte Nere (PN) and Palizzi (GP); almost the entire Pietre Cotte (PC) crater from the north via the west to the south of the Fossa edifice and the recent Gran Cratere (GC) in the northwest of the cone show low compressive horizontal stress (see Fig. 6 for locations). The rims of the Forgia Vecchia crater (FV) at the northern flanks of La Fossa are also visible in terms of a lower compressive horizontal stress regime but less pronounced than the other crater rims. The bottom of the Forgia Vecchia crater, in turn, shows high compressive horizontal stress. The amplitude of compressive stress there is almost as high as detected at the bottom of the recent crater. Besides these regions, higher compressive values of the horizontal stress can also be identified between other topographic highs such as in the northeast- ern part of the Fossa cone between the Punte Nere and the Pietre Cotte crater rims and between the Pietre Cotte crater and Gran Cratere. In the following section we shall see that the fumarole temperature field generally follows these patterns predicted by the finite element models.

\section{Fumarole temperature mapping}

Infrared measurements provide a simple but sophisticated way to obtain a view about the location of fumaroles and the fluid migration close to the surface (Harris and Maciejewski, 2000; Chiodini et al., 2007; Harris et al., 2009). At the Fossa cone, thermal anomalies are present mainly in the northern to northeastern and also in the southern sectors, and have been detailed by earlier 
workers (cf. Barde-Cabusson et al., 2009 and Harris et al., 2009 and references therein). Although the spatial distribution of those high temperature fields was investigated, earlier authors focussed either on imaging on a local scale using infrared cameras (e.g. Harris et al., 2009) or on conewide measurements at selected points using manual probing and spatial interpolation (BardeCabusson et al., 2009). No large-scale infrared survey that allows more complete and spatially dense temperature measurements was undertaken yet. Therefore, using infrared imaging and photogrammetric image analysis and geocoding, we were able to generate an inclusive temperature field map and compare it to the theoretical stress field models described above.

\subsection{Field observation method}

Thermal and digital images were collected using a forward looking infrared thermal camera (FLIR type P620) with a resolution of $640 \times 480$ pixels, equipped with a $24^{\circ}$ zoom objective that allows a $0.66 \mathrm{mrad}$ instantaneous field of view. The camera operates in the $7.5-13 \mathrm{~mm}$ waveband and was calibrated to temperatures in the range of $0{ }^{\circ} \mathrm{C}$ to $500{ }^{\circ} \mathrm{C}$, therefore covering the expected temperature field of the Fossa cone. We locally validated the remotely sensed temperature by thermocouple in situ measurements. All data was acquired in Nov/Dec 2009.

Emissivity of the target, atmospheric temperature and camera- target distance were considered. We follow earlier workers in the same region and define an emissivity of 0.95 which is slightly lower than that proposed earlier (Harris and Maciejewski, 2000). This emissivity we approved by value comparison to independent in situ measurements. Because steam may absorb the radiation coming from high temperature fumaroles, we avoided imaging the fumarole zones during intense degassing, as occurring during the early morning hours.

Due to the cone shaped morphology of the studied volcano, the images are affected by strong perspective phenomena. Viewing angle and viewing distance change vertically and horizontally within each image and therefore pixel resolution changes as well throughout the picture. The effect of varying distance is resulting in pixel sizes varying by more than one order of magnitude $\left(0.02-0.43 \mathrm{~m}^{2}\right)$, being larger with increasing distance.

To obtain a nearly complete temperature image mosaic, in total over 300 images were taken from different positions of the crater-inner and external flanks, leaving us with almost 9 million data points. The strategy was to position the camera on the slope opposite to the target area, and then obtain an image. For later georeferencing, we measured the position of prominent features (large boulders, trees, fumaroles) by GPS. Areas that we could not target using this strategy included (i) the narrow plain extending from the Gran Crater rim northward to Pietre Cotte, (ii) the outer flank of Punte Nere, and (iii) the sea facing flank.

The infrared images were selected based on their quality (e.g. absence of fumarole gas and sharpness) and imported into a geographic information system (ArcGIS). By combination with aerial images and GPS referencing we could geocode the images. The result is a photo-mosaic showing cone-wide details of the thermal anomalies (Fig. 9). The main advantage of photomosaicking is that a larger area could be imaged at high resolution in short time by foot. Disadvantages might be related to shadowing effects.

In the following, we first describe selected photographs of the Fossa crater region in detail, followed by the temperature pattern observed in the geocoded photo-mosaic.

\subsection{Survey results}


At the inner crater wall, infrared images show that along the southern flank, well defined thermal anomalies with different intensi- ties were found (Fig. 10). First, at top, relatively low temperatures are seen. Second, a high temperature anomaly that is well defined by a narrow horizontal strip at the Gran Cratere cliff is eminent. This is probably located within the Caruggi formation (for lithology terminol- ogy see De Astis et al., 2006). Here, from the thermal contrast we can clearly identify localised vents and elongated fractures, with pixel temperatures ranging between $45{ }^{\circ} \mathrm{C}$ and $70{ }^{\circ} \mathrm{C}$ (q2 in Fig. 10). Another more diffuse thermal anomaly is located further below, showing a diffuse increased thermal transmission of $30-40{ }^{\circ} \mathrm{C}$ (lithology $\mathrm{t}$ in Fig. 10). The observed temperature range hence sharply drops at lithology contrasts. Therefore, thermal imaging locally suggests that the locations of elevated temperature fields are influenced by lithology.

The northern flank of the main crater is known to be the site where the most intense degassing occurs and onto which earlier infrared studies focused (cf. Harris et al., 2009 and references therein). Infrared images taken of the northern crater wall show a large thermal anomaly that spreads along the slope. This area is characterised by diffuse, augmented heat flux including clustered but also scattered vents. Most pronounced temperature vents appear to occur in groups and along fractures that may be tens of meters long. The strike direction of these vent alignments follows a rough systematic geometric pattern with respect to the crater centre, including circumferential trends (C-vents), radial trends (R-vents) or, more often, oblique trends (O-vents). We interpret these trends to be linked to a fracture system (Fig. 11). The scattered vents in the lower and middle zone show temperatures from $40{ }^{\circ} \mathrm{C}$ up to $50{ }^{\circ} \mathrm{C}$, whereas selected pixels at clustered vents and fractures in the upper zone display temperatures up to $111^{\circ} \mathrm{C}$. At the bottom of the crater, no elevated temperatures can be identified. Because of the locally detected vent alignments, thermal imaging suggests a structural influence on temperature fields.

A view of the entire Fossa cone is provided by a synthesis of 56 selected images, geocoded and assembled to a mosaic. Because the images were taken over the course of two days, especially the mid-day acquisitions are affected by warmer background temperatures. We follow the approach by Barde-Cabusson et al. (2009) and consider only temperatures above a background temperature $\left(30{ }^{\circ} \mathrm{C}\right)$ as a signature of hydrothermal fluid circulations. The infrared thermal map shows isolated regions of elevated temperatures, generally being most pronounced at higher elevations and along the morphologic limits of various crater generations. Therefore, in a large-scale view, elevated temperatures appear to be eminent at morphologically elevated regions. We note, however, that no major diffuse temperature increase can be recognised, rather it appears that elevated temperatures are recorded at predominantly very local sites. A profile in $\mathrm{N}-\mathrm{S}$ direction shows the relationship of the temperature field and topography (Fig. 12). Temperature values are taken as a stack of a $250 \mathrm{~m}$ wide strip. The profile shows that fumaroles and areas of diffuse increased heat flux are mainly found at the rims of the craters. Therefore, the large- scale picture of the thermal imaging results implies that the locations of elevated temperature fields are influenced by topography.

A synthesis of the temperature field survey is given in Fig. 12, in comparison to the finite element stress field models. To display only significantly elevated thermal areas, we show only those pixels above $35^{\circ} \mathrm{C}$. As seen, zones of elevated temperatures are found in regions of relatively low compressive stress, which has important implications as discussed below.

\section{Discussion}

High temperature fields associated with fumaroles are observed at many active volcanoes, providing a window into the state of activity beneath. Therefore, fumarole measurements are 
often part of volcano monitoring programs, which is also why their location and dynamics need to be investigated. It is the temperature field, which allows mapping and spatially dense monitoring of such fumaroles, assuming that the sites and processes of fumaroles, fluid paths and high temperature fields are the same (Harris and Maciejewski, 2000; Chiodini et al., 2007; Harris et al., 2009). The cratered summit of Vulcano Island is a fumarole type example, which we investigated through finite element stress field modelling and infrared mapping. Our work suggests that the fumarole locations have to be regarded scale-dependent, being a combined result of three major factors: topography, tectonics and lithology (Fig. 13) that will be discussed further below.

\subsection{Limitations of the model and infrared approach}

In the FEM model, settings were used and assumptions made that might have had an influence on the results. We explored the effects of the model boundaries and the geometry in very detail, by comparison to previous gravitational loading models. Furthermore, in models not shown in this paper, we explored the effect of different rock densities and Lamé parameters, both influence stresses, yet the general pattern as described in this work remains valid.

Our FEM model was homogeneous, even though our own field observations suggest that the outcropping material is heterogeneous (cf. De Astis et al., 2006). Materials of contrasting stiffness and their distribution in the volcanic pile are not considered in the numerical model although they might have an influence on the state of stress in the Earth's crust (e.g. Gudmundsson and Philipp, 2006). As the distribution, layering and extend of mechanical anisotropies are not possible to quantify, and may further provide uncertainties, however, we decided to investigate the model under the homogeneity assumption.

No other forces than the load of gravity were applied in the FEM model of this work, neither a local pressure source associated with a contracting magma body (Aubert et al., 2008) nor a regional stress trend. The latter was excluded because there is substantial debate on the regional state of stress in the central sector of the Aeolian Arc (Mazzuoli et al., 1995; Bonaccorso, 2002; Argnani et al., 2007). Nevertheless, our stress models show that topographic loading can explain field observations well and can help to predicted fumarole expressions at cratered volcanoes.

The infrared technique we adopted has an instrumental error of $\sim 2{ }^{\circ} \mathrm{C}$ and is affected by physical and geometrical parameters that may introduce further errors in measuring temperatures (Ball and Pinkerton, 2006). Emissivity and relative humidity yield errors that are negligible for our purposes. Assuming an emissivity e $=0.95$ and a mean relative humidity of $50 \%$, we obtained a good agreement of the infrared measurements with independent K-type thermocouple measurements. Considered distance ranges lead to an error similar to the instrumental one. The viewing inclination onto a surface, often ranging from $40^{\circ}$ to $90^{\circ}$ with respect to the target surface, is causing an emissivity decrease in the range of 1-3\% (Sobrino and Cuenca, 1999). The overall amplitude of these errors may play a role when one would like to define a threshold between ground temperature and weak hydrothermal related anomalies. For the significant tempera- ture anomalies described in this work, however, also the sum of all these errors is negligible.

Of larger effect at the Fossa cone are shadowing phenomena, which may have prohibited detection of some important fumaroles. In comparison with in situ probing results (BardeCabusson et al., 2009), we conjecture that only those regions remained in shadow where no major fumarole activity is eminent. Combining our data with airborne infrared data in the future might provide better wide scale information. Despite the discussed limitations, the method we applied to 
image thermal anomalies can be successfully used for fast and logistically inexpensive thermal detection in volcanic regions, especially when the anomalies are wide and intense compared to the background values.

\subsection{Comparison of the thermal field measurements to earlier results}

Infrared surveys at Vulcano were well investigated before and illustrated the flux and variability of fumarole activity at unprecedented levels of detail (Harris and Maciejewski, 2000; Chiodini et al., 2007; Harris et al., 2009). However, these earlier infrared campaigns focussed on very local appearance of fumaroles, mostly inside the Fossa crater on its northeastern rim where degassing is apparent. No large-scale high resolution mapping was performed yet. A cone-wide temperature map was provided based on in situ probing, whereby at certain soil depth (usually about $30 \mathrm{~cm}$ ) the local temperature is recorded, which is repeated along tracks and later on interpolated to obtain a spatial information (Revil et al., 2008; Barde-Cabusson et al., 2009). Temper- ature recordings we provided in this work generally compare well with the ones obtained by Revil et al. (2008) and Barde-Cabusson et al. (2009) although different techniques were used. Due to the different

spatial resolution, however, the infrared observations provided here are of much higher detail. Just by using one single thermal image, over 300,000 pixels are recorded, which is already two to three orders of magnitude higher than point-wise probing allows. The main difference to these previous results is that sites of elevated temperature are found to be very local only. While the punctual measurements suggest a wide field of elevated temperatures, our work shows that these are in fact much more localised. Again, interpolation might have blurred the information, which is why our approach appears to be valid and more detailed in the spatial domain.

\subsection{Factors controlling the sites of fumaroles}

We suggest distinguishing the fumarole locations in a process and scale-dependent context, which is (a) the topographic control in large-scale, and (b) the lithology control and (c) the structural control in small-cale (Fig. 13).

(1) Topographic control: Our field observations could reveal that the temperature shows maxima where the topography is high, such as the rims of the nested craters on the Fossa cone. This is found to be in agreement with finite element models, showing that at these zones the horizontal stress field is less compres- sive. The stress field model of the Fossa cone shows that at depth, there is a region where $\sigma_{1}$ is vertical and $\sigma_{3}$ is horizontal and normal to the plane of projection, thus parallel to the rims of the crater (Figs. 4 and 5). This would lead to radial pathways of hydrofractures at depth (Anderson, 1951). This outcome is supported by observations made elsewhere on the orientation of dikes in the field (McGuire and Pullen, 1989; Tibaldi et al., 2009) and also in analogue experiments (McGuire and Pullen, 1989; Walter and Troll, 2003; Acocella and Tibaldi, 2005) showing radial directions. The orientation of the principal stresses changes close to the surface, for example near caldera rims and fault scarps. There, $\sigma_{1}$ becomes parallel to the surface what is also observed in our numerical model (Figs. 4 and 5). Hot fluids escape predominately along the concentric rims of the nested craters (Figs. 9 and 12). High temperature anomalies can be found at the crater rims of Palizzi in the south, Pietre Cotte in the north and Gran Cratere in the northeast of the edifice. In addition, the horizontal compressive stress is low at these areas, encouraging fluid ascent. The numerical model predicts a more compressive stress regime at the bottom of the recent crater what is in correspondence to the temperature distribution showing that the base of the recent crater is colder than $20^{\circ} \mathrm{C}$ (cf. Revil et al., 2008). 
No degassing sites were observed at the bottom of the Fossa crater. This may again be supported by the models, as the crater floor corresponds to the area of high compressive values of the horizontal stress. However, we note that this observa- tion might also be related to a less permeable layer at the bottom of the crater that makes it difficult for fluids to migrate through. This sedimentary cover is probably the result of material deposition derived from the flanks of the Fossa cone (De Astis et al., 2006).

(2) Lithology control: Lithological heterogeneities like bedding surfaces or the interface of lithological units may provide migration ways or barriers for ascending fluids in volcanic edifices (Gudmundsson et al., 2002; Barde-Cabusson et al., 2009). Field observations of the inner southern flank of Gran Cratere reveal that the high temperature anomalies there are situated in the stratified hydromagmatic tuff but not in the pyroclastic deposits under and overlaying this lithology (Figs. 2 and 10). Apparently, the hydromagmatic tuff is more prone to the percolation of fluids, thus has a higher permeability, than the neighbouring deposits (cf. Revil et al., 2008). The hydro- magmatic tuff is attributed to belong to the Caruggi and the Pietre Cotte formation whereas the pyroclastics are thought having formed during the Gran Cratere eruptive stage (De Astis et al., 2006). The lithology control may also be of importance at depth at the Fossa cone, but shape and continuation of these strata at depth remains speculative.

(3) Structural control: The ascent and migration of fluids may be controlled by structural features as already suggested earlier (e.g. Barde-Cabusson et al., 2009). High permeable fracture zones are probably the most widely recognised pathways influencing fumarolic vent locations. These may have a linear fault-like geometry but may also be curved or oblique. Vulcano is affected by a regional N-S striking fault system - an orientation that we could not identify in thermal anomalies, however. Although the Fossa cone on Vulcano also does not show any significant faults at the surface and the identification of ring faults remains obscured, our own observations reveal that high temperature anomalies at the northern flank of Gran Cratere are bound to fractures and cracks located along the crater rim. Fluids could flow more easily on the fractures because these structures will increase the permeability of rocks exponentially and provide locations for the migration of high temperature fluids (Harris et al., 2009). The observed structural trends may have various reasons that are not distinguishable from our data, such as near surface slumping, cauldron type fractures, pressurised reservoir sources or regional tectonic influence.

\subsection{Implications}

In this paper we showed that fumarole sites on the Fossa cone on Vulcano Island are partially controlled by the load of the volcanic pile. This outcome can be applied to other volcanoes that also have a pronounced topography and show degassing activity at the rims of the central craters, like Lastarria in the Central Andes (Ruch et al., 2009) and Somma-Vesuvius in Italy (Chiodini et al., 2001). With the approach of the FEM it seems possible to infer the ascent path of fluids in volcanic edifices. Furthermore, if the possible influences of topographic control, lithology and fractures are understood, pre- dictions about migrating hydrothermal activity as well of (hydro-) magmatic vents might be feasible. Although the initiation of fumarolic vent migration at the Fossa edifice is guided by other mechanisms like sealing, the topography body forces could be a factor in controlling the arrangement of new fumarolic sites. Harris and Maciejewski (2000) report that the fumarolic field migrated downward on the inner flanks of the crater, yet showing a concentric pattern with respect to the crater floor. As the concentric pattern agrees with our model predictions, the gravitational force might influence the migration of new degassing sites. It remains to be investigated whether observed eruption vent migration, such as shifting from the northeast to the southwest and north during the eruptive history of the Fossa cone (Blanco- 
Montenegro et al., 2007) was following the same concepts.

\section{Conclusions}

Numerical models of the Fossa cone, Vulcano Island, were compared to field observations and the surface temperature distri- bution obtained by an infrared campaign. The stress field in the models suggests a topographic control on the large-scale distribution of the fumaroles: The degassing sites are located at the rims of the nested craters of the volcanic edifice where compression is low. However, a closer look shows that other processes like lithology and fracture zones influence the exact positions of the fumaroles. Therefore, the appearance and prediction of fumarolic activity and associated hazards of active volcanoes has to be considered as the combined control of loading, permeability and faulting.

\section{Acknowledgements}

Professor P. Baldi from the University of Bologna, Italy, is kindly acknowledged for making the DEM data available. We thank Astrid Hartmann for field assistance, and Andrea Manconi for discussion at an earlier stage. Some figures were created with the help of GMT (Wessel and Smith, 1991). The paper benefited from helpful reviews of Adelina Geyer and Valerio Acocella. Financial support came from GFZ Potsdam and the Integrated Earth Observation System (Network EOS-II) to create methodological and organizational synergies.

\section{References}

Acocella, V., Tibaldi, A., 2005. Dike propagation driven by volcano collapse: a general model tested at Stromboli, Italy. Geophysical Research Letters 32 (L08308), doi:10.1029/2004GL022248.

Acocella, V., Neri, M., Scarlato, P., 2006. Understanding shallow magma emplacement at volcanoes: Orthogonal feeder dikes during the 2002-2003 Stromboli (Italy) eruption. Geophysical Research Letters 33 (17), L17310.

Anderson, E., 1951. The dynamics of faulting, 2nd edn. Oliver and Boyd, Edinburgh.

Argnani, A., Serpelloni, E., Bonazzi, C., 2007. Pattern of deformation around the central Aeolian Islands: evidence from multichannel seismics and GPS data. Terra Nova 19, 317-323.

Arnórsson, S., 1995. Geothermal systems in Iceland: structure and conceptual models - I. High-temperature areas. Geothermics 24 (5/6), 564-602.

Aubert, M., Diliberto, S., Finizola, A., Chébli, Y., 2008. Double origin of hydrothermal convective flux variations in the Fossa of Vulcano (Italy). Bulletin of Vulcanology 70, 743-751.

Baldi, P., Bonvalot, S., Briole, P., Marsella, M., 2000. Digital photogrammetry and kinematic GPS applied to the monitoring of Vulcano Island, Aeolian Arc, Italy. Geophysical Journal International 142, 1-19.

Ball, M., Pinkerton, H., 2006. Factors affecting the accuracy of thermal imaging cameras in volcanology. Journal of Geophysical Research 111 (B11203), doi:10.1029/ 2005JB003829.

Barde-Cabusson, S., Finizola, S., Revil, A., Ricci, T., Piscitelli, S., Rizzo, E., Angeletti, B., Balasco, M., Bennati, L., Byrdina, S., Carzaniga, N., Crespy, A., Di Gangi, F., Morin, J., Perrone, A., Rossi, M., Roulleau, E., Suski, B., Villeneuve, N., 2009. New geological insights and structural control on fluid circulation in La Fossa cone (Vulcano, Aeolian Islands, Italy). Journal of Volcanology and Geothermal Research 185 (3), 231-245.

Bell, F.G., 1992. Engineering properties of soils and rocks, 3rd edn. Butterworth Heinemann, Oxford.

Blanco-Montenegro, I., De Ritis, R., Chiappini, M., 2007. Imaging and modelling the subsurface structure of volcanic 
calderas with high-resolution aeromagnetic data at Vulcano (Aeolian Islands, Italy). Bulletin of Volcanology 69, 643659.

Bonaccorso, A., 2002. Ground deformation of the southern sector of the Aeolian islands volcanic arc from geodetic data. Tectonophysics 351, 181-192.

Chadwick, W.W., Dieterich, J.H., 1995. Mechanical modeling of circumferential and radial dike intrusion on Galapagos volcanoes. Journal of Volcanology and Geothermal Research 66, 37-52.

Chesner, C.A., Rose, W.I., 1991. Stratigraphy of the Toba Tuffs and the evolution of the Toba Caldera Complex, Sumatra, Indonesia. Bulletin of Volcanology 53, 343-356.

Chiodini, G., Marini, L., Russo, M., 2001. Geochemical evidence for the existence of high- temperature hydrothermal brines at Vesuvio volcano, Italy. Geochimica et Cosmochimica Acta 65 (13), 2129-2147.

Chiodini, G., Vilardo, G., Augusti, V., Granieri, D., Caliro, S., Minopoli, C., Terranova, C., 2007. Thermal monitoring of hydrothermal activity by permanent infrared automatic stations: results obtained at Solfatara di Pozzuoli, Campi Flegrei (Italy). Journal of Geophysical Research 112 (B12206), doi:10.1029/2007JB005140.

De Astis, G., La Volpe, L., Peccerillo, A., Civetta, L., De Astis, G., La Volpe, L., Peccerillo, A., Civetta, L., 1997. Volcanological and petrological evolution of Vulcano Island (Aeolian Arc, southern Tyrrhenian Sea). Journal of Geophysical Research 102 (B4), 8021-8050.

De Astis, G., Dellino, P., La Volpe, L., Lucchi, F., Tranne, C.A., 2006. Geological map of the Volcano Island. Istituto Nazionale di Geofisica e Vulcanologia, Naples.

Dieterich, J.H., 1988. Growth and persistence of Hawaiian Volcanic Rift Zones. Journal of Geophysical Research 93 (B5), 4258-4270.

Favalli, M., Karátson, D., Mazzuoli, R., Pareschi, M.T., Ventura, G., 2005. Volcanic geomorphology and tectonics of the Aeolian archipelago (Southern Italy) based on integrated DEM data. Bulletin of Volcanology 68, 157-170.

Fiske, R.S., Jackson, E.D., 1972. Orientation and growth of Hawaiian volcanic rifts: the effect of regional structure and gravitational stresses. Proceedings of the Royal Society of London, Series A: Mathematical and Physical Sciences 329 (1578), 299-326.

Granieri, D., Carapezza, M.L., Chiodini, G., Avino, R., Caliro, S., Ranaldi, M., Ricci, T., Tarchini, L., 2006. Correlated increase in $\mathrm{CO} 2$ fumarolic content and diffuse emission from La Fossa crater (Vulcano, Italy): evidence of volcanic unrest or increasing gas release from a stationary deep magma body? Geophysical Research Letters 33 (L13316), doi:10.1029/2006GL026460.

Gudmundsson, A., 2009. Toughness and failure of volcanic edifices. Tectonophysics 471, 27-35.

Gudmundsson, A., Philipp, S.L., 2006. How local stress fields prevent volcanic eruptions. Journal of Volcanology and Geothermal Research 158 (34), 257-268.

Gudmundsson, A., Fjeldskaar, I., Brenner, S., 2002. Propagation pathways and fluid transport of hydrofractures in jointed and layered rocks in geothermal fields. Journal of Volcanology and Geothermal Research 116, 257-278.

Harris, A.J.L., Maciejewski, A.J.H., 2000. Thermal surveys of the Vulcano Fossa fumarole field 1994-1999: evidence for fumarole migration and sealing. Journal of Volcanology and Geothermal Research 102, 119-147.

Harris, A.J.L., Lodato, L., Dehn, J., Spampinato, L., 2009. Thermal characterization of the Vulcano fumarole field. Bulletin of Volcanology 71, 441-458.

Iverson, R.M., Reid, M.E., 1992. Gravity-driven groundwater flow and slope failure potential 1. Elastic effective-stress model. Water Resources Research 28 (3), 925-938.

Martel, S.J., Muller, J.R., 2000. A two-dimensional boundary element method for calculating elastic gravitational 
stresses in slopes. Pure and Applied Geophysics

157, 989-1007.Mazzuoli, R., Tortorici, L., Ventura, G., 1995. Oblique rifting in Salina, Lipari and Vulcano Islands (Aeolian Islands, Southern Tyrrhenian Sea, Italy). Terra Nova 7, 444-452.

McGuire, W.J., Pullen, A.D., 1989. Location and orientation of eruptive fissures ad feeder-dykes at Mount Etna; influence of gravitational and regional tectonic stress regimes. Journal of Volcanology and Geothermal Research 38 (34), 325-344.

Pareschi, M., Ranci, M., Valenza, M., Graziani, G., 1999. The assessment of volcanic gas hazard by means of numerical models: an example from Vulcano Island (Sicily). Geophysical Research Letters 26 (10), 1405-1408.

Revil, A., Finizola, A., Piscitelli, S., Rizzo, E., Ricci, T., Crespy, A., Angeletti, B., Balasco, M., Barde-Cabusson, S., Bennati, L., Bolève, A., Byrdina, S., Carzaniga, N., Gangi, F.D., Morin, J., Perrone, A., Rossi, M., Roulleau, E., Suski, B., 2008. Inner structure of La Fossa di Vulcano (Vulcano Island, southern Tyrrhenian Sea, Italy) revealed by high resolution electric resistivity tomography coupled with self-potential, temperature, and $\mathrm{CO} 2$ diffuse degassing measurements. Journal of Geophysical Research 113 (B07207), doi:10.1029/2007JB005394.

Ruch, J., Manconi, A., Zeni, G., Solaro, G., Pepe, A., Shirzaei, M., Walter, T., Lanari, R., 2009. Stress transfer in the Lazufre volcanic area, central Andes. Geophysical Research Letters 36 (22), L22303.

Santacroce, R., Cristofolini, R., La Volpe, L., Orsi, G., Rosi, M., 2003. Italian active volcanoes. Episodes 26 (3), $227-$ 234.

Savage, W.Z., Swolfs, H.S., Powers, P.S., 1985. Gravitational stresses in long symmetric ridges and valleys. International Journal of Rock Mechanics and Mining Sciences \& Geomechanics Abstracts 22 (5), 291-302.

Schöpa, A., 2010, Topographic controls on fluid paths: a numerical simulation for Gran Cratere, Vulcano Island, Italy. unpublished diploma thesis, TU Bergakademie Freiberg.

Sobrino, J.A., Cuenca, J., 1999. Angular variation of thermal infrared emissivity for some natural surfaces from natural measurements. Applied Optics 38, 257-262.

Tibaldi, A., Corazzato, C., Marani, M., Gamberi, F., 2009. Subaerial-submarine evidence of structures feeding magma to Stromboli Volcano, Italy, and relations with edifice flank failure and creep. Tectonophysics 469, 112-136.

Ventura, G., 1994. Tectonics, structural evolution and caldera formation on Vulcano Island (Aeolian Archipelago, southern Tyrrhenian Sea). Journal of Volcanology and Geothermal Research 60, 207-224.

Walter, T., Schmincke, H., 2002. Rifting, recurrent landsliding and Miocene structural reorganization on NW-Tenerife (Canary Islands). International Journal of Earth Sciences 91 (4), 615-628.

Walter, T., Troll, V., 2003. Experiments on rift zone evolution in unstable volcanic edifices. Journal of Volcanology and Geothermal Research 127 (12), 107-120.

Wessel, P., Smith, W., 1991. Free software helps map and display data. Eos Transactions, AGU 72, 441. 


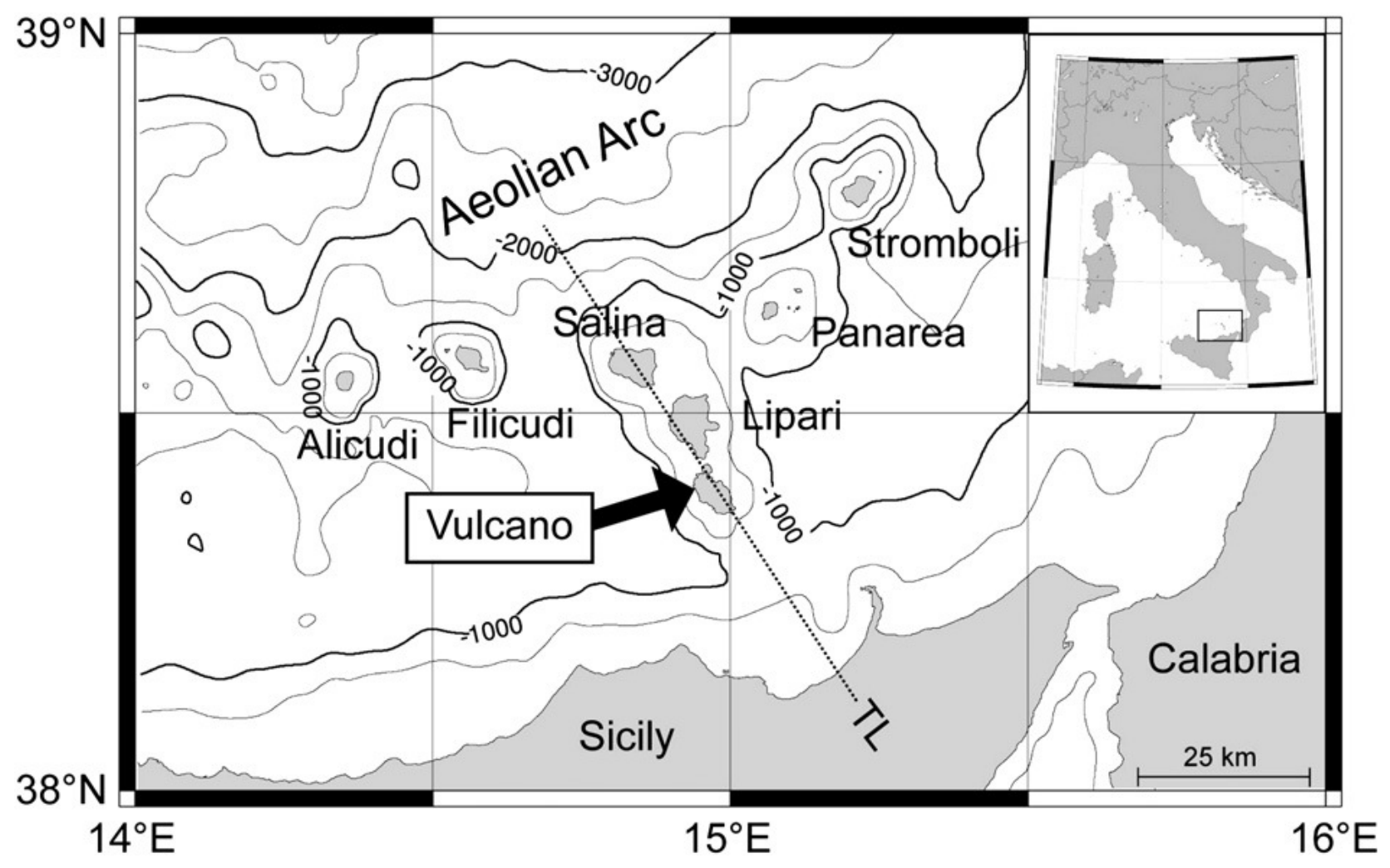

Fig. 1. Sketch map of the Aeolian Islands with bathymetry in $m$ of the southern Tyrrhenian Sea. The location of the Tindari-Letojanni fault system (TL) is also indicated. 


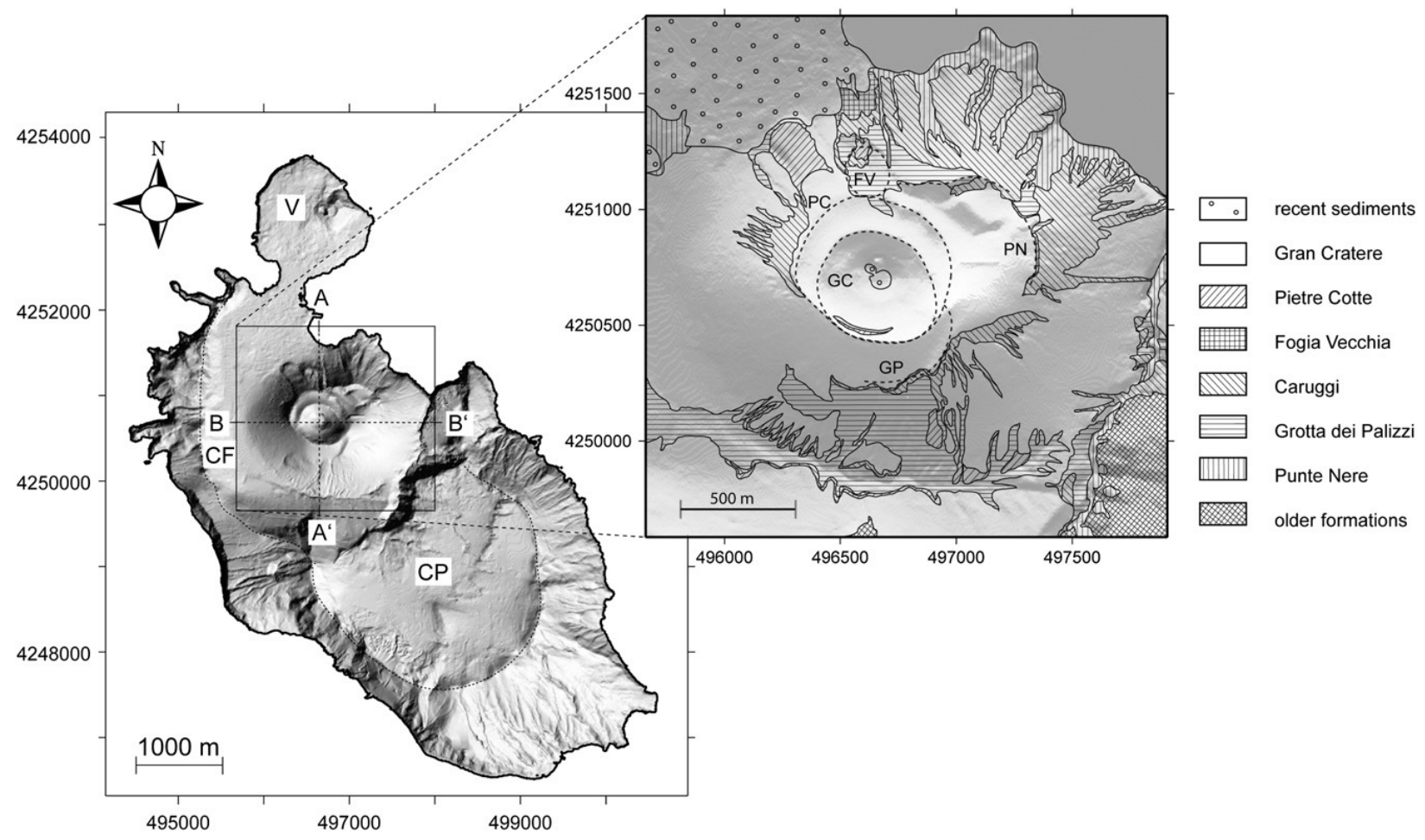

Fig. 2. Shaded relief map of Vulcano Island and simplified geological map of the Fossa cone (De Astis et al., 2006; Barde-Cabusson et al., 2009). On the map of the island, dotted lines represent caldera rims with Caldera del Piano (CP) and Caldera della Fossa (CF); (V) is the peninsula of Vulcanello. The box shows the region used for the three-dimensional model of the Fossa cone. Location of the N-S (A-A') and the WE (B-B') cross-section is also indicated. Broken lines on the geological sketch map of La Fossa are crater rims of the distinct eruptive cycles: (PN) Punta Nere, (GP) Grotta dei Palizzi, (FV) Forgia Vecchia, (PC) Pietre Cotte and (GC) Gran Cratere. Coordinate system is UTM, zone 33 S, WGS 84. 


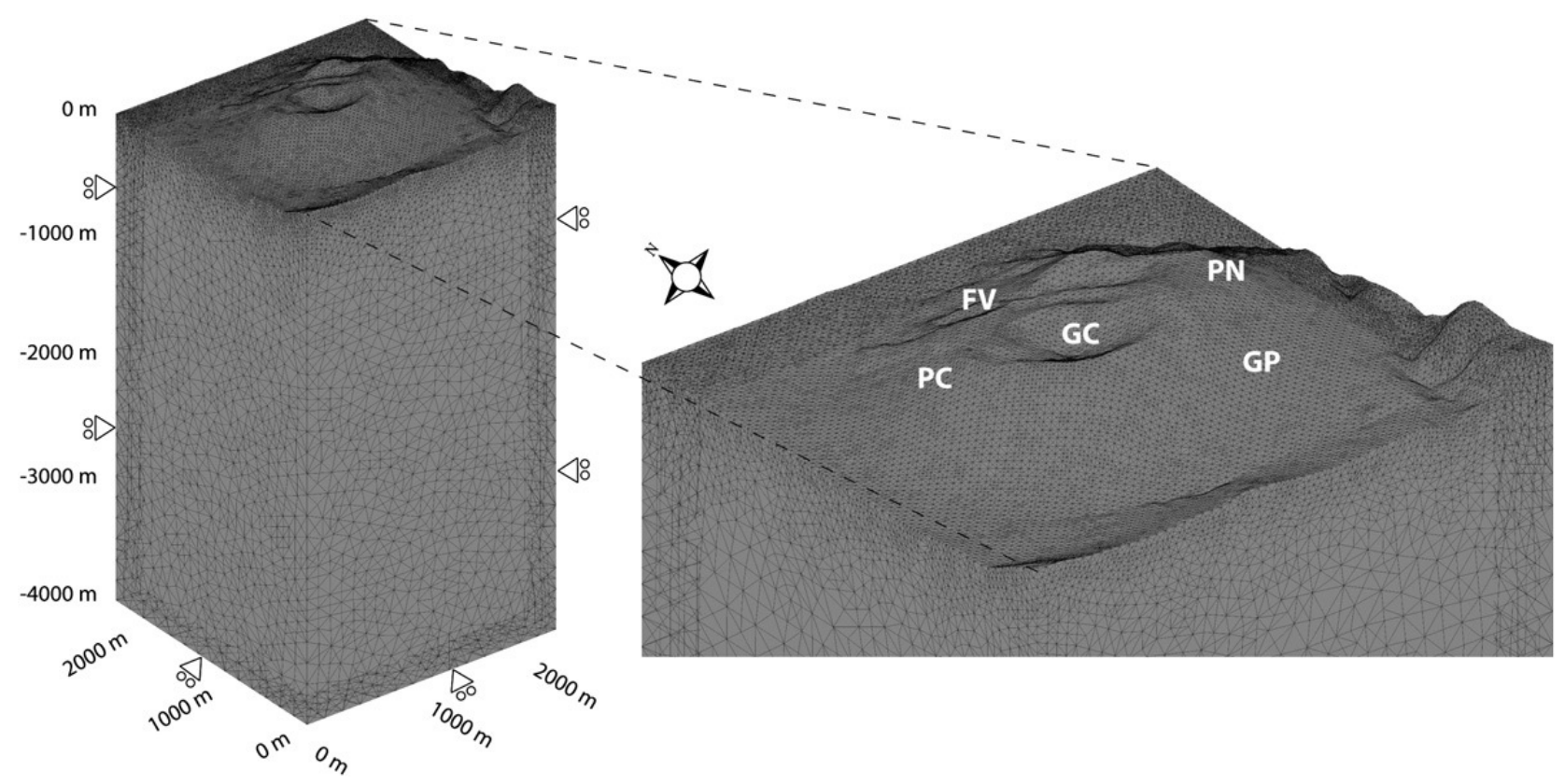

Fig. 3. Configuration of the numerical model, a $2250 \mathrm{~m} \times 22250 \mathrm{~m} \times(4000 \mathrm{~m}+$ elevation $)$ box in threedimensional geometry. The sketch includes the finite element mesh and the boundary conditions. The Earth's surface is treated as a free surface (displacement in all directions allowed). At the other boundaries, displacement is prohibited normal to the boundaries (zero displacement in (z) direction at the bottom boundary, zero displacement in $(\mathrm{x})$ direction at the eastern and western boundary, zero displacement in $(\mathrm{y})$ direction at the northern and southern boundary). The material of the model is linear elastic and isotropic with a density $v$ of $2700 \mathrm{~kg} / \mathrm{m}^{3}$, a Poison's ratio @ of 0.25 and a Young's modulus E of $50 \mathrm{GPa}$. The gravitational load is defined as $\mathrm{F}=\mathrm{ggh}$ where $\varrho$ is the density of the material, $\mathrm{g}$ the gravitational acceleration of the Earth and $h$ the height of the topographic feature. 
a) Maximum compressive principal stress $\left(\sigma_{1}\right)$ trajectories

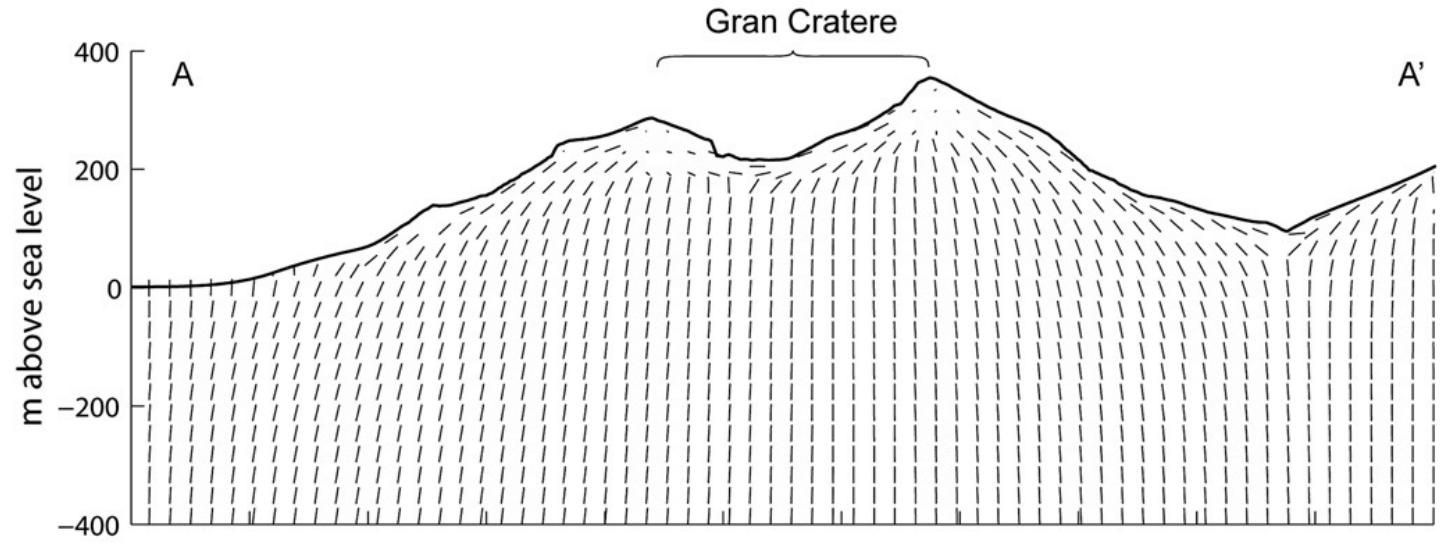

b) Minimum compressive principal stress $\left(\sigma_{3}\right)$ trajectories

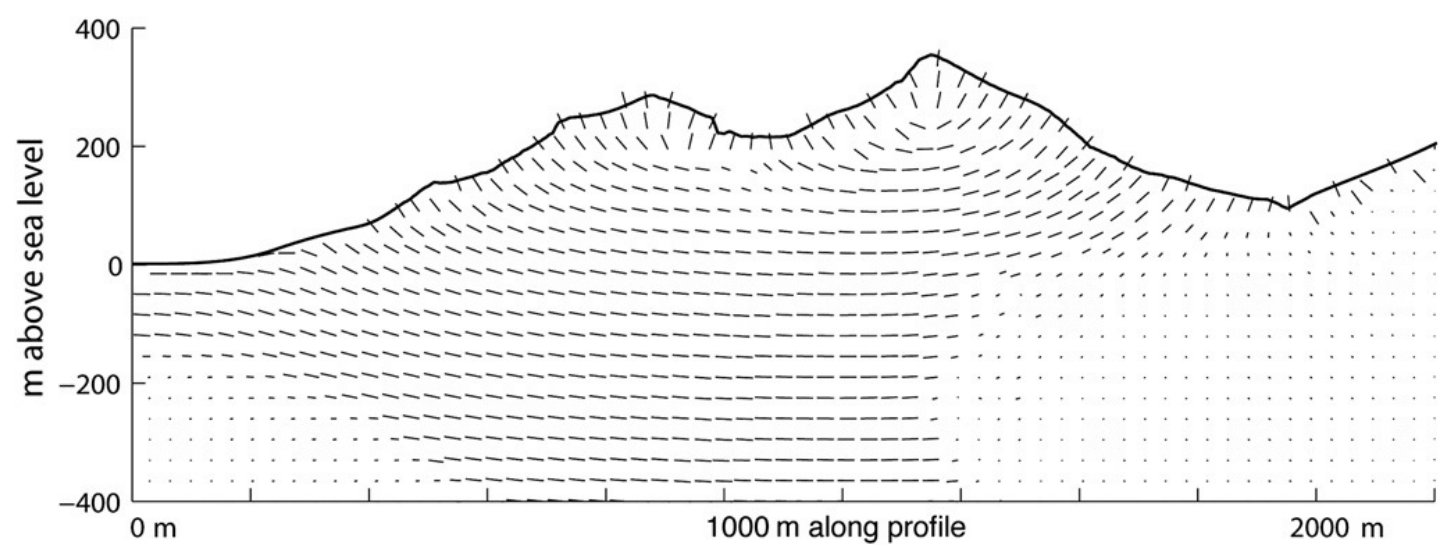

Fig. 4. Trajectories parallel to a) the maximum compressive principal stress $\sigma_{1}$ and b) the minimum compressive principal stress $\sigma_{3}$ in a $\mathrm{N}-\mathrm{S}$ cross-section of the Fossa cone. 
a) maximum compressive principal stress ( $\left.\sigma_{1}\right)$ trajectories

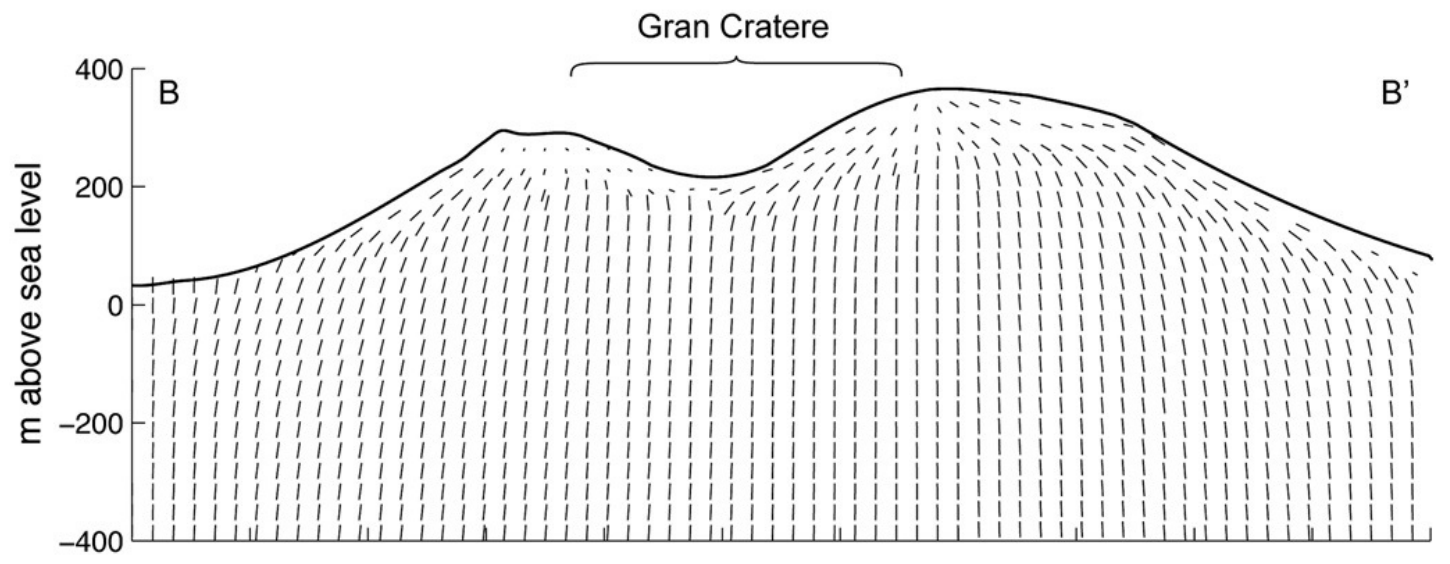

b) minimum compressive principal stress ( $\left.\sigma_{3}\right)$ trajectories

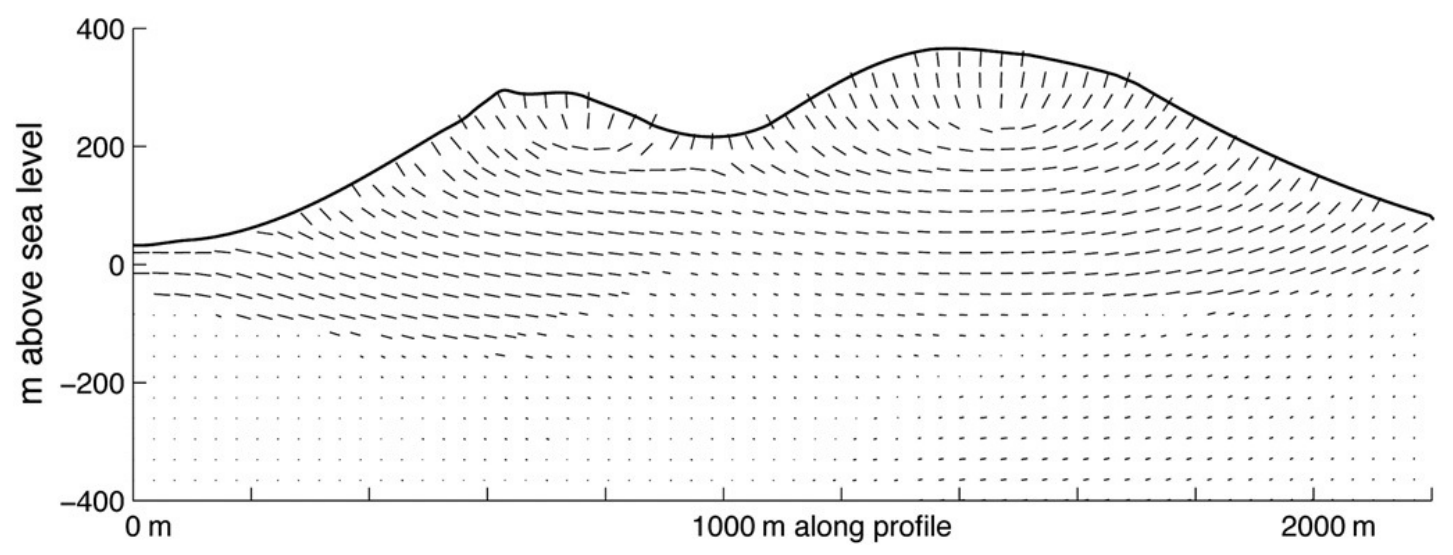

Fig. 5. Trajectories parallel to a) the maximum compressive principal stress $\sigma 1$ and b) the minimum compressive principal stress $\sigma 3$ in a W-E cross-section of the Fossa cone. 


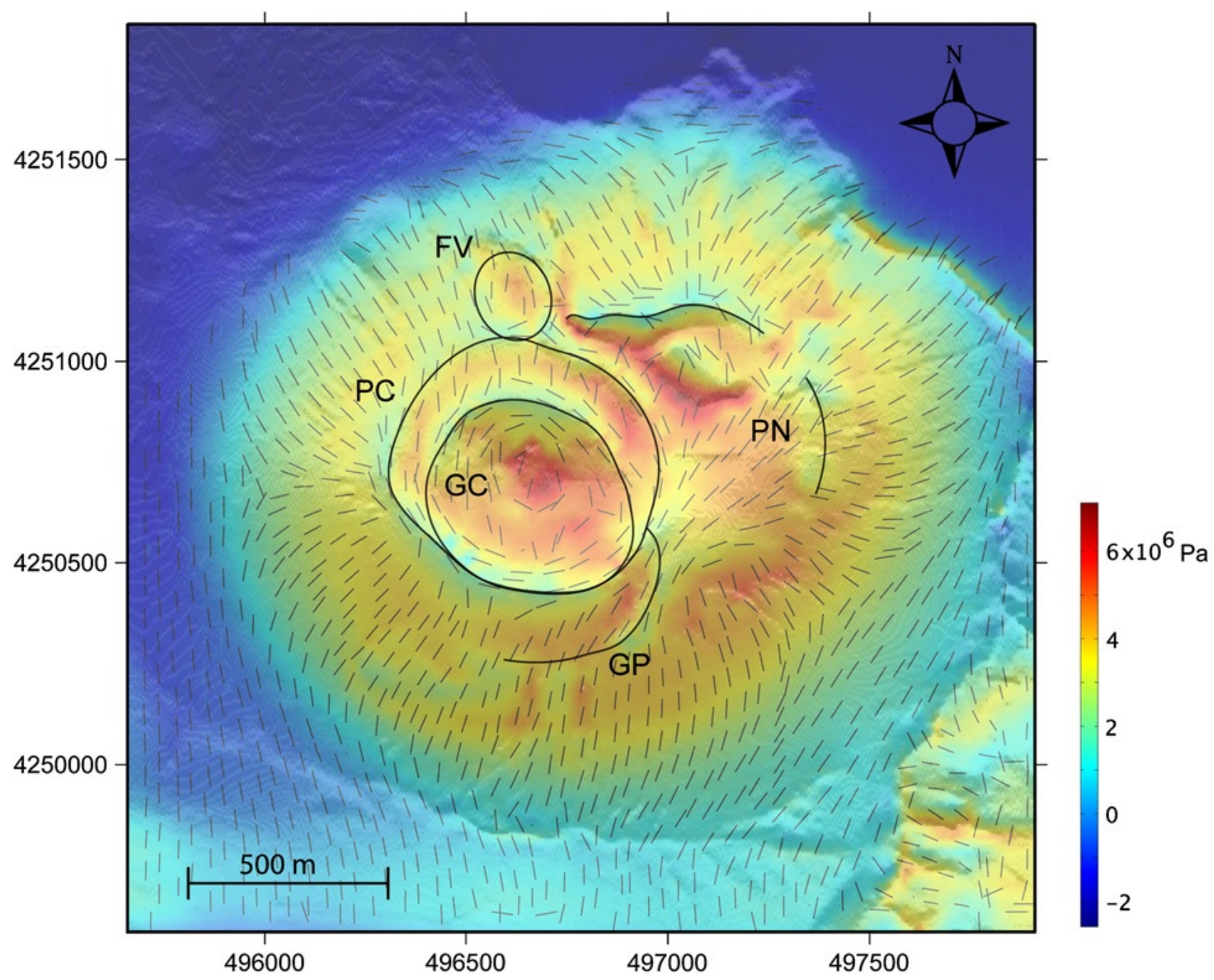

Fig. 6. Trajectories parallel to the maximum compressive principal stress $\sigma_{1}$ and magnitude of the horizontal stress in a surface map view of the Fossa cone, underlain by a shaded relief map. Solid lines are crater rims of the distinct eruptive stages: (PN) Punta Nere, (GP) Grotta dei Palizzi, (FV) Forgia Vecchia, (PC) Pietre Cotte and (GC) Gran Cratere. 
a) Vertical stress

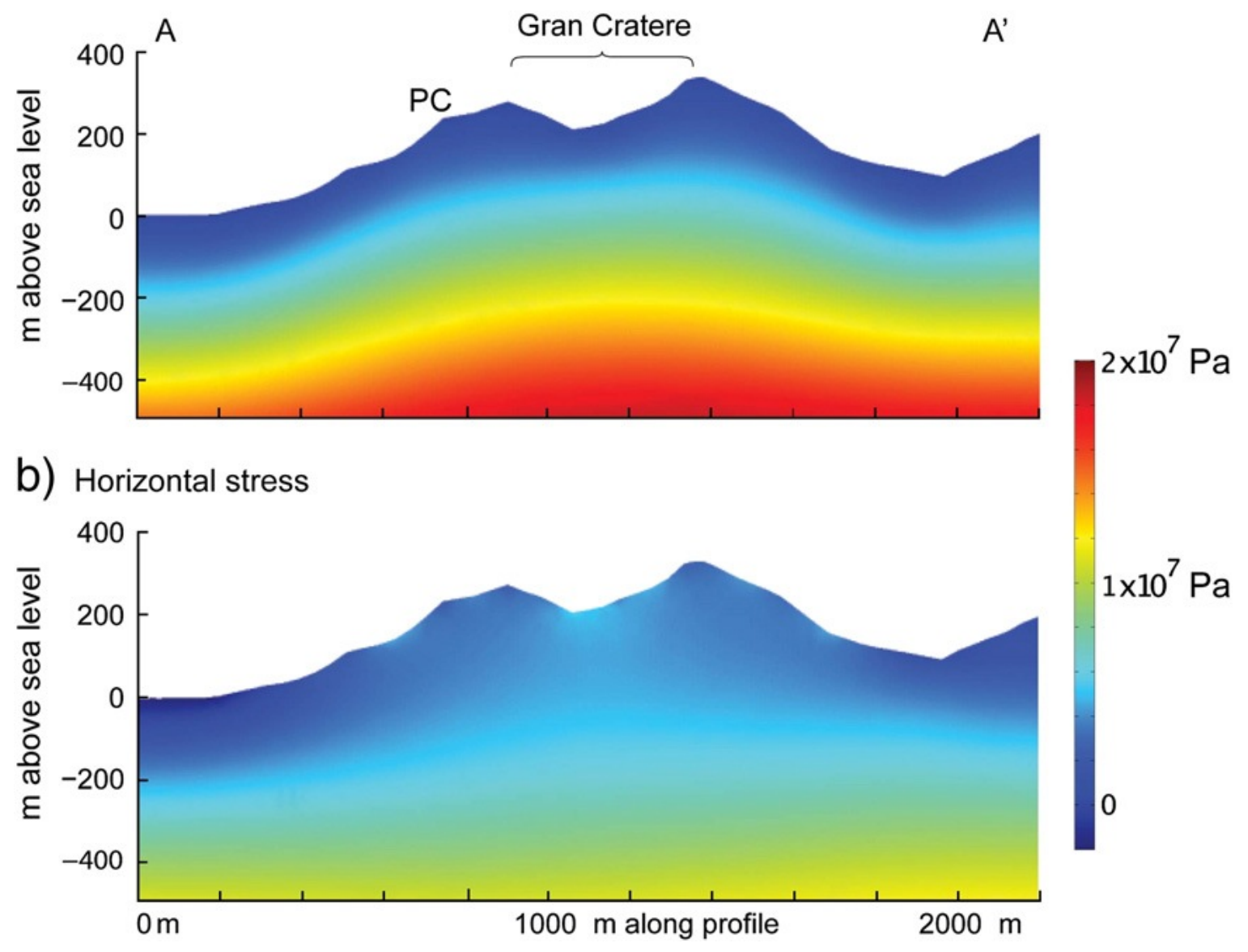

Fig. 7. Magnitudes of the a) vertical and b) horizontal stress in a N-S cross-section of the Fossa cone. 


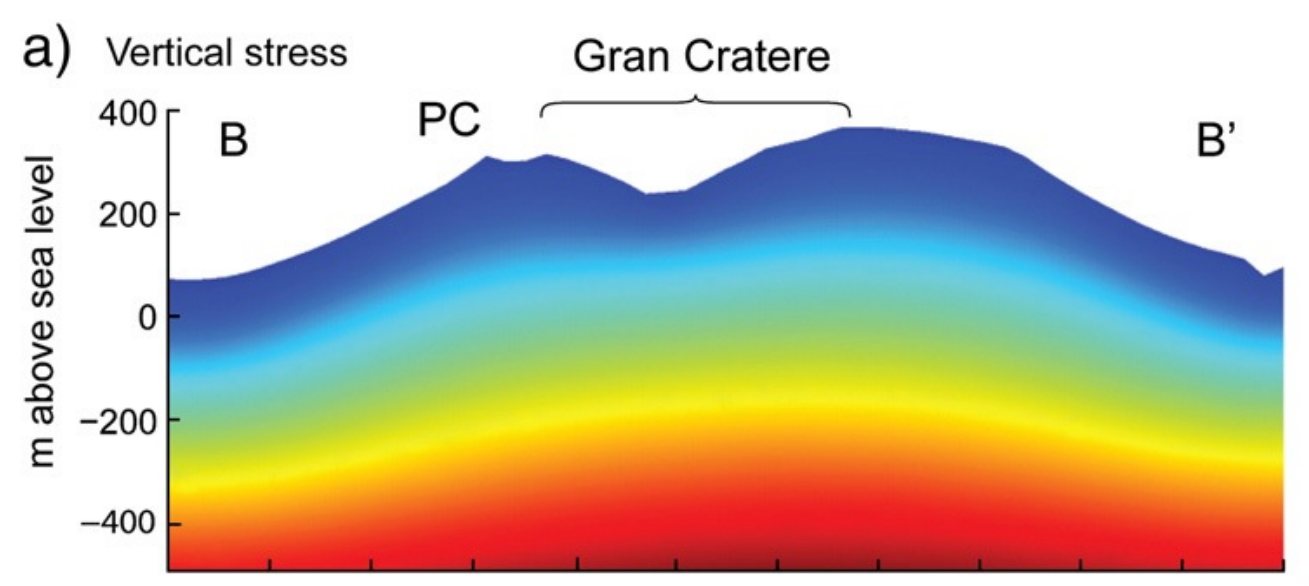

b) Horizontal stress

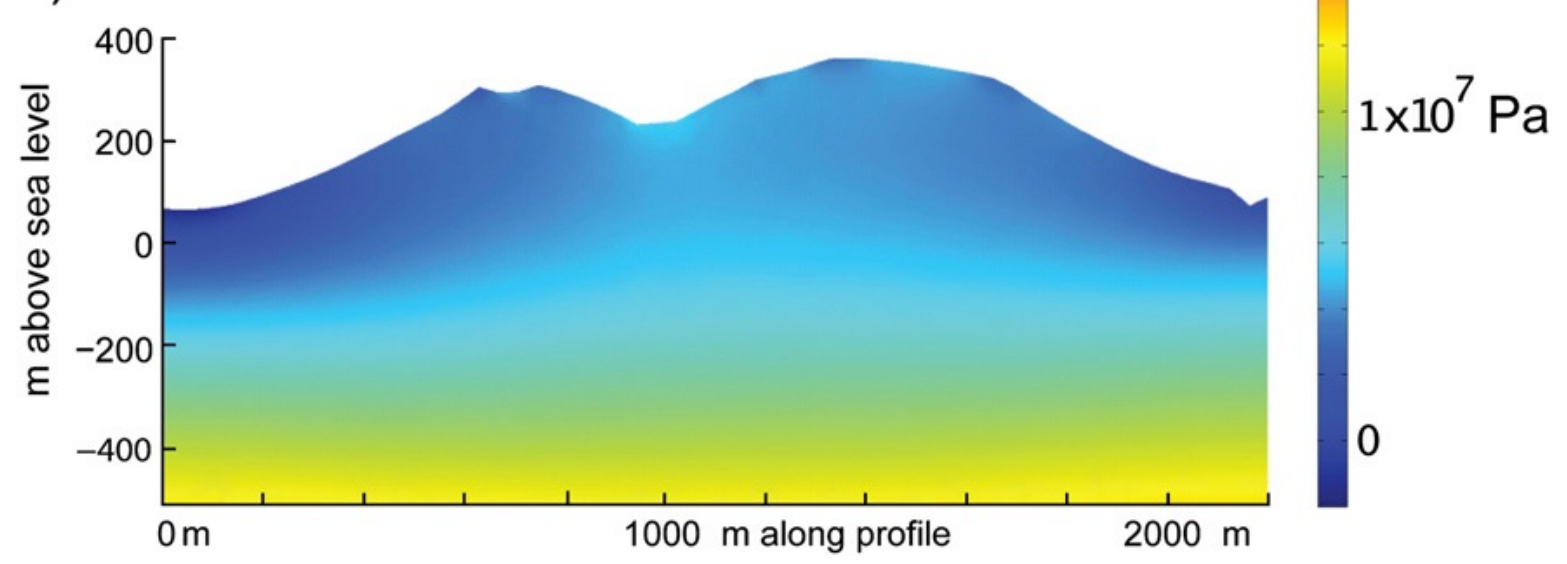

Fig. 8. Magnitudes of the a) vertical and b) horizontal stress in a W-E cross-section of the Fossa cone. 


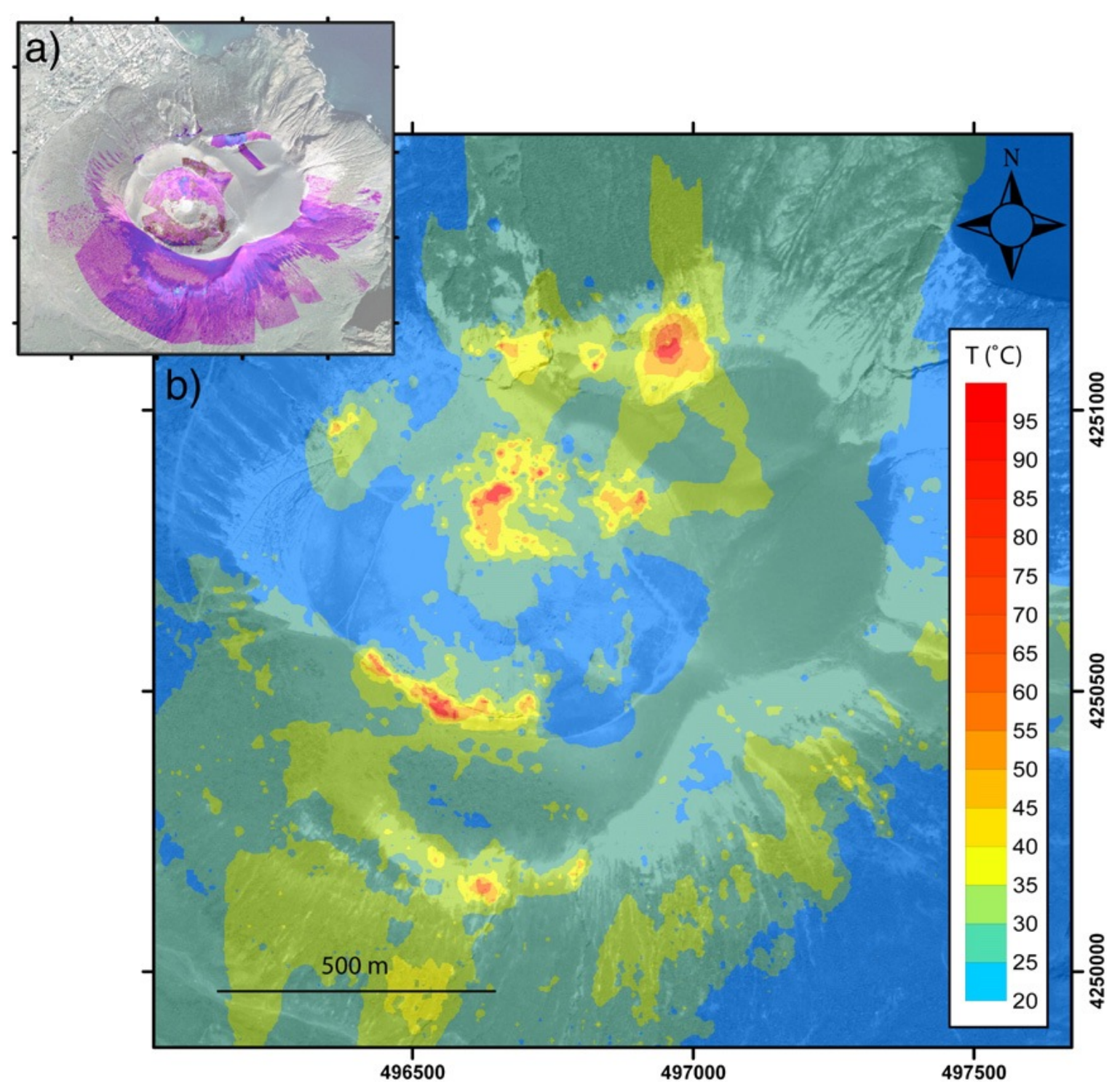

Fig. 9. (a) Map view of geocoded infrared mosaic. (b) Extracted temperature pixels above background temperature. 


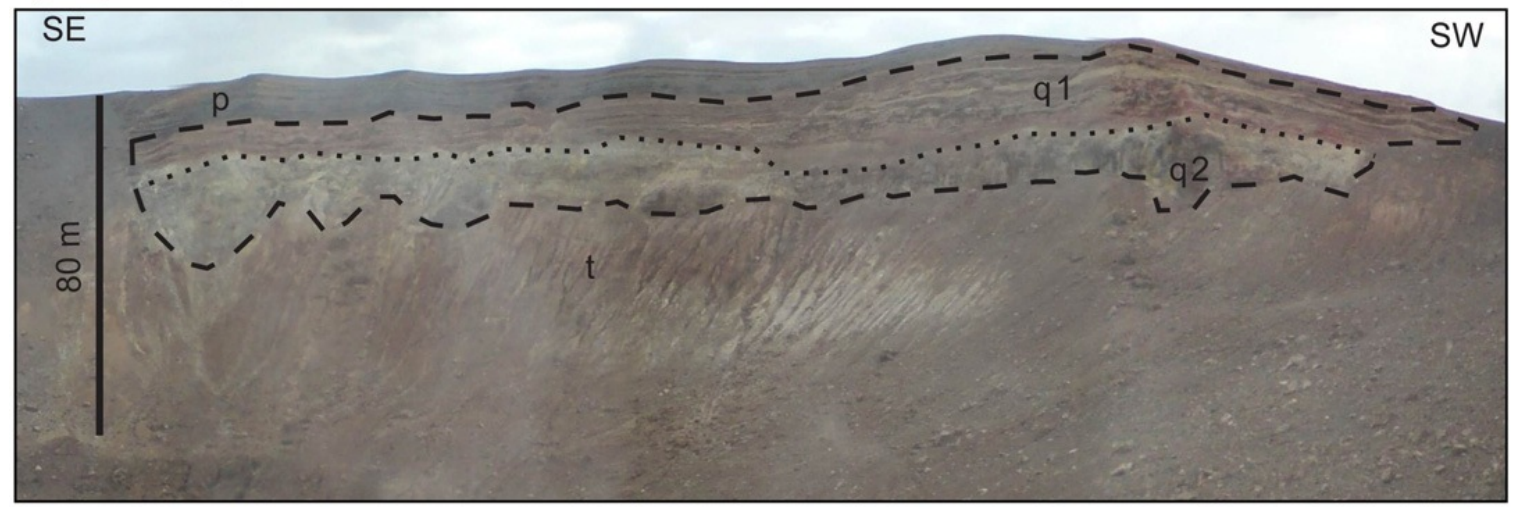

b) Infrared image of the southern crater wall

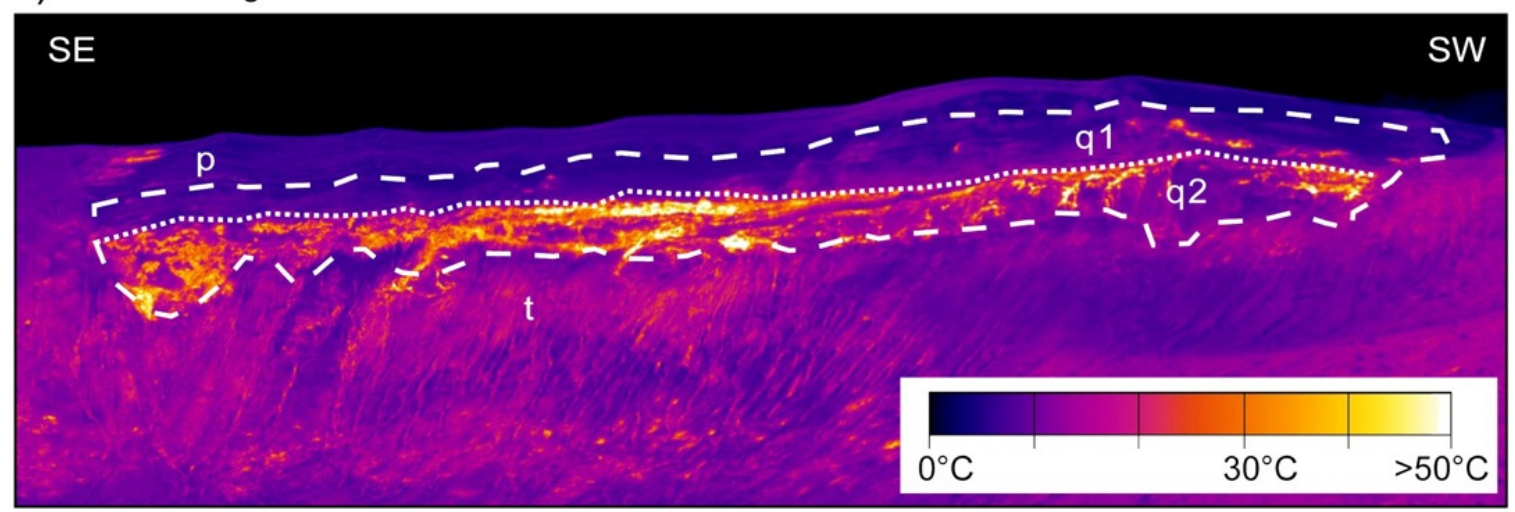

Fig. 10. a) Digital and b) thermal photo-mosaic of the southern internal flank of Gran Cratere. Lithologies as in Revil et al. (2008) include p) ashes, q1) hydromagmatic tuff, q2) hydromagmatic tuff with hydrothermal weathering and t) pyroclastic deposits. Localised high heat flux occurs in the encircled region of lithology q2 at fractures and cracks, diffuse high heat flux is observed in the region of lithology t. 
a) Digital image of the northern crater wall

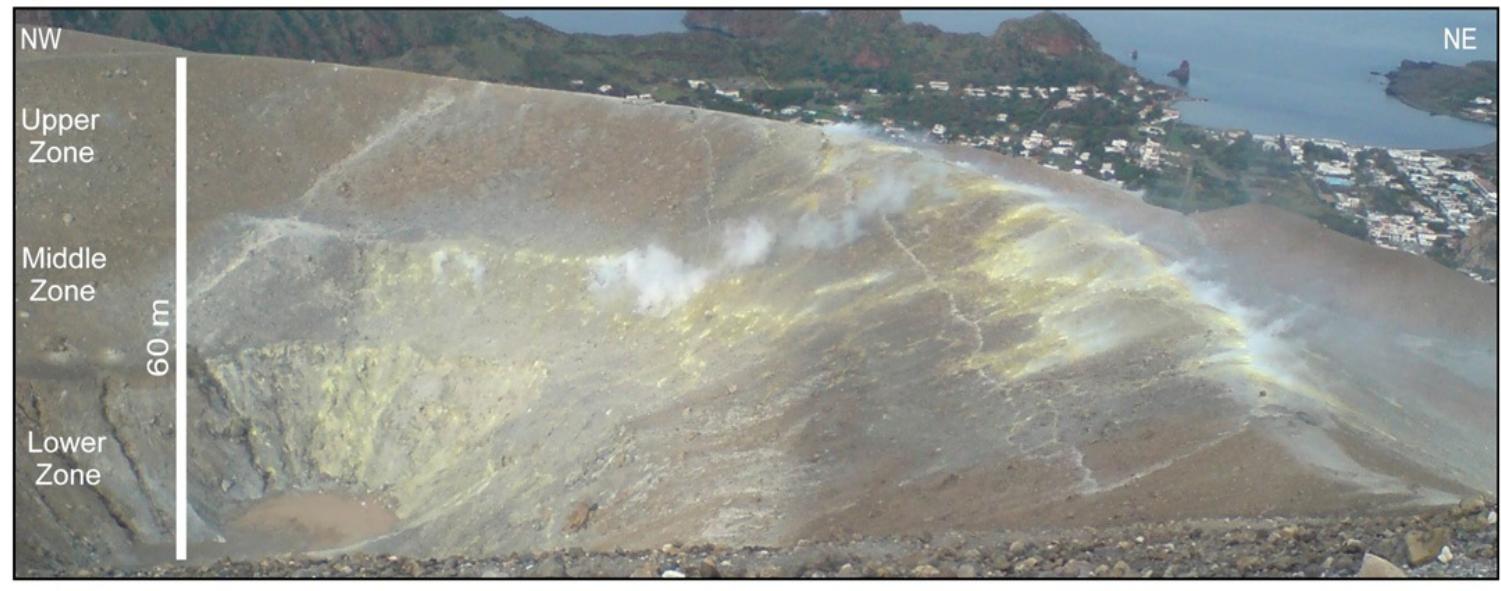

b) Infrared image of the northern crater wall

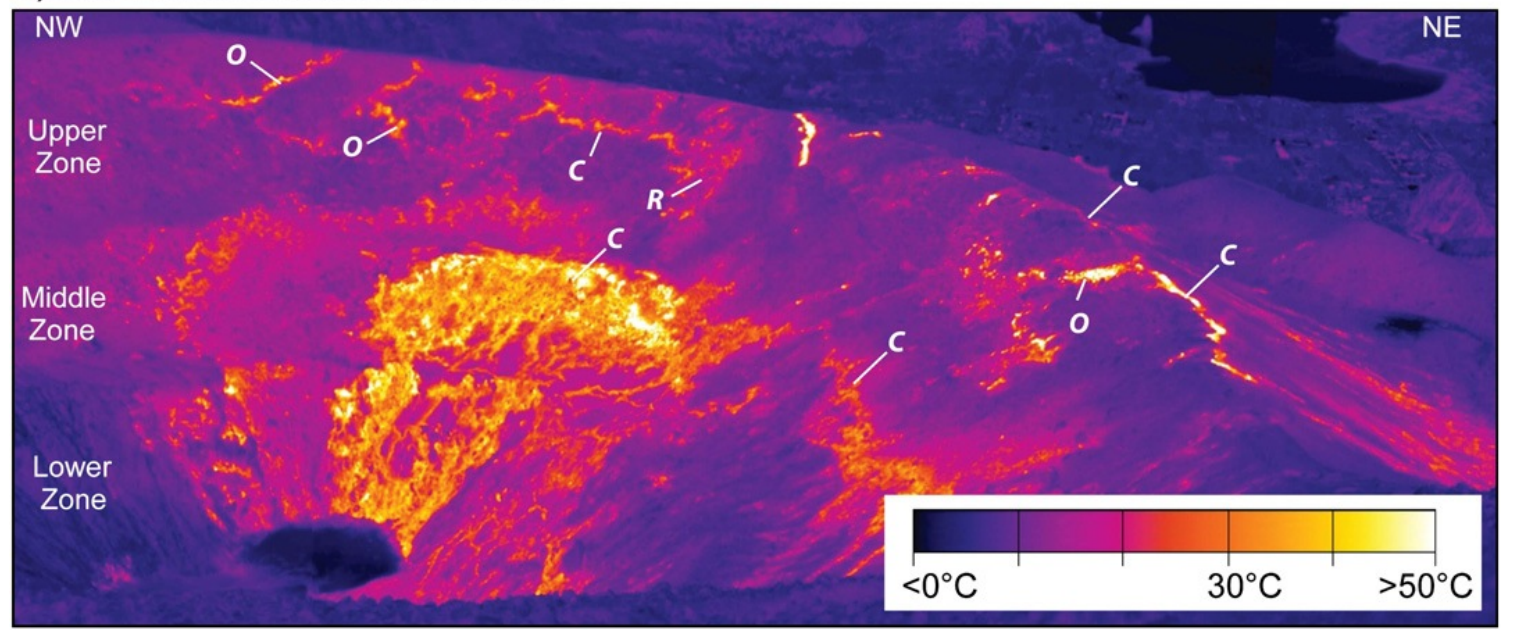

Fig. 11. a) Digital and b) thermal photo-mosaic of the northern internal flank of Gran Crater with indication of different zones as described by Harris and Maciejewski (2000). The strike direction of vent alignments with respect to the crater centre is indicated, including circumferential trends ( $\mathrm{C}$-vents), radial trends ( $\mathrm{R}$ vents) and oblique trends (O-vents). 

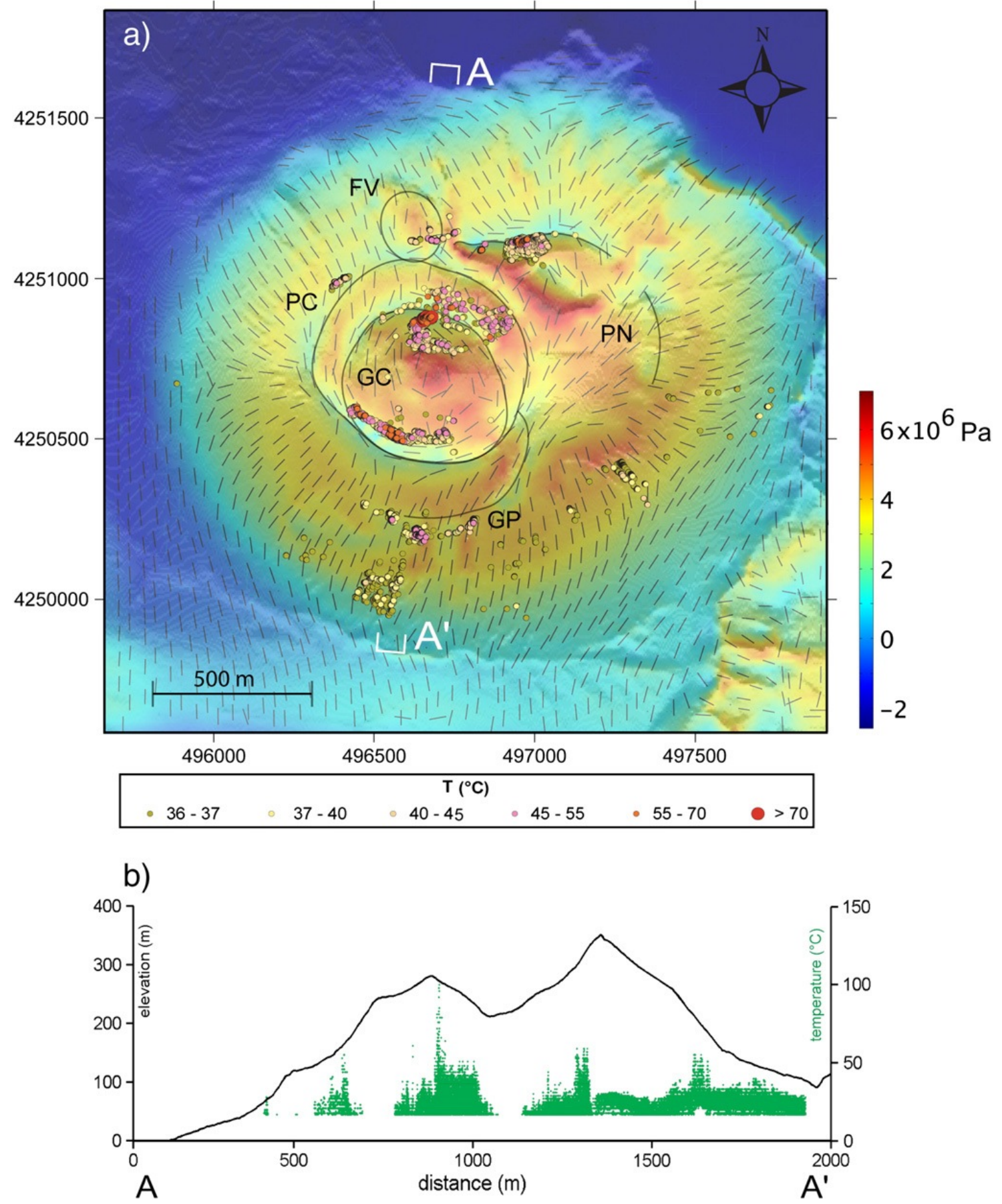

Fig. 12. (a) Map of the distribution and the intensities of thermal anomalies at the Fossa cone (superimposed circles on a shaded relief map with $\sigma_{1}$-trajectories and magnitude of the horizontal stress). (b) N-S profile of the temperature distribution along a strip $\left(\mathrm{A}^{\left.-\mathrm{A}^{\prime}\right)}\right.$ through the main fumarole fields. Missing data corresponds to flat areas and areas which could not be imaged. Only pixels above $17{ }^{\circ} \mathrm{C}$ background temperature are shown. Note the good match between temperature and topographic expression. 

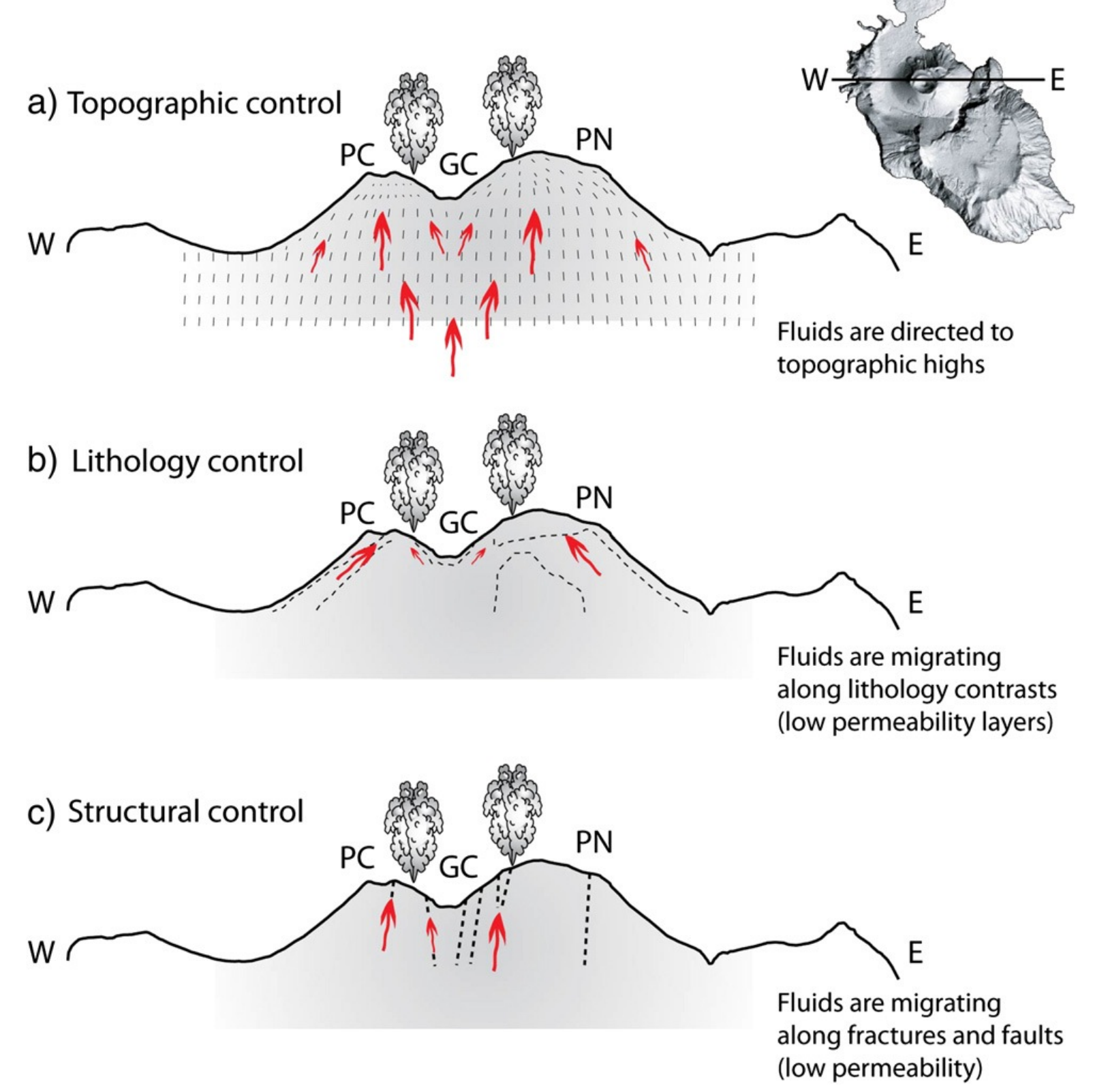

Fig. 13. Schematic cross-section summarising the controls of ascending fluids in a cratered volcano, here the Fossa cone, Vulcano Island: 1) Effect of edifice load indicated by $\sigma_{1}$-trajectories, 2) migration at interfaces of lithological strata, 3) propagation along fractures and cracks. 